\title{
PROBLEMAS FUNDAMENTALES \\ DE LA FILOSOFfA
}




\title{
COLECCIÓN ARISTEO
}

Druaton ros

\section{LUIS ALFONSO Y VIRGILIO O. SORDELLI}

\author{
6 \\ FILOSOFIA
}

QUEDA HECHO EL DEPठ́STTO QUE PREVIENE LA LEY 11.723

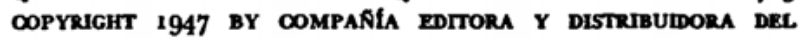
PLATA, S. R. L., ENTRE Ríos 1256, BUENOS AIRES. CARACTERISTICAS GRÁFICAS REGISTRADAS. IMPRESO EN LA ARGENTINA 


\section{GEORG SIMMEL}

\section{PROBLEMAS}

\section{FUNDAMENTALES DE LA FILOSOFÍA}

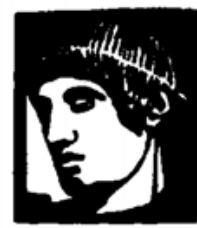

EDITOKA Y DISTRIBUIDORA DEL PLATA BUENOS AIRES 
GEORG SIMMEL

Nació en Berlin el so do marzo do 18 g8.

Murió en Estrasburgo el 26 de octubre de 1918.

Título en alemán:

DEE HAUPTPROBLEME DER PHILOSOPHIE

Traducción de Susana Molinari y Eduardo Schulzen 